\title{
Challenges for Managed Care from 340B Contract Pharmacies
}

\author{
Adam J. Fein, PhD
}

\begin{abstract}
SUMMARY
The federal 340B Drug Pricing Program has expanded rapidly, with important yet still unmeasured impact on both managed care practice and policies. Notably, providers increasingly rely on external, contract pharmacies to extend 340B pricing to a broad set of patients. In 2014, 1 in 4 U.S. retail, mail, and specialty pharmacy locations acted as contract pharmacies for 340B-covered entities. This commentary discusses crucial ways in which $340 \mathrm{~B}$ growth is affecting managed care pharmacy through formulary rebates, profits from managed care paid prescriptions, disruption of retail pharmacy networks, and reduced generic dispensing rates. Managed care should become more engaged in the discussion on how the 340B program should evolve and offer policy proposals to mitigate the challenges being encountered. There is also an urgent need for objective, transparent research on the $340 \mathrm{~B}$ program's costs, benefits, and implications for managed care pharmacy and practice.
\end{abstract}

J Manag Care Spec Pharm. 2016;22(3):197-203

Copyright @ 2016, Academy of Managed Care Pharmacy. All rights reserved.

$\mathrm{M}$ any managed care pharmacy professionals and researchers may be unfamiliar with the structure of and controversy surrounding the federal 340B Drug Pricing Program. However, the program's rapid growth is having important yet still unmeasured impact on managed care practice and policies. During the past decade, purchases made through the 340B program have grown by $800 \%$, from $\$ 0.8$ billion in 2004 to $\$ 7.2$ billion in 2013. ${ }^{1}$ The number of 340B-covered sites increased by $9.6 \%$ per year from 2005 to $2014 .^{2}$ Hospitals, which are $46 \%$ percent of 340B-covered entity sites, account for nearly $90 \%$ of $340 \mathrm{~B}$ purchases. In 2013, hospitals received 340B discounts on an estimated $25 \%$ of their drug purchases, compared with only $3 \%$ of 2004 purchases. ${ }^{3}$ Twenty-five percent of retail, mail, and specialty pharmacies have aligned with hospitals and other health care providers that participate in the $340 \mathrm{~B}$ program. ${ }^{4}$

This commentary describes the structure of the 340B Drug Pricing Program and the health care entities, products, and patients eligible for $340 \mathrm{~B}$ pricing. Burgeoning contract pharmacy arrangements between 340B-covered entities and external pharmacies are also discussed. Key managed care pharmacy issues are identified, including formulary rebates, profits from managed care paid prescriptions, disruption of retail pharmacy networks, and reduced generic dispensing rates. Suggestions are offered for necessary research and policy actions.

\section{Overview of the 340B Program}

\section{Program Purpose}

The 340B Drug Pricing Program was created by Section 602 of the Veterans Health Care Act of 1992 (PL 102-585), which established Section 340B of the Public Health Service Act. The Health Resources and Services Administration (HRSA), an agency of the U.S. Department of Health and Human Services (HHS), manages the program through its Office of Pharmacy Affairs.

The intent of the 340B program has been controversial. The conference committee report accompanying the original legislation stated that "the Committee intends to enable these entities to stretch scarce Federal resources as far as possible, reaching more eligible patients and providing more comprehensive services." ${ }^{5}$ Notably, the legislation did not specify or restrict how covered entities should use any funds generated from the program. Some argue that covered entities can use discounts to reduce their cost of operations. Others suggest the program be reformed so it explicitly improves access to outpatient medications for vulnerable and underserved patients. ${ }^{6}$ It is beyond the scope of this commentary to evaluate the many claims and counterclaims made by the program's advocates and critics. Instead, we address only those issues related to contract pharmacy use and implications for managed care pharmacy.

\section{Products and Pricing}

The 340B program mandates that pharmaceutical manufacturers provide outpatient drugs to certain health care entitiesknown as eligible covered entities-at significant discounts. The following products are eligible for 340B pricing: FDAapproved prescription drugs; over-the-counter drugs when prescribed; biological products (other than vaccines) dispensed only by a prescription; and FDA-approved insulin. ${ }^{7}$ Products that are ineligible for the 340B program include inpatient drugs, vaccines, drugs without a National Drug Code number, and drugs not directly reimbursed by a payer. Covered entities must have a tracking system to ensure that drugs purchased through the $340 \mathrm{~B}$ program are not used for hospital inpatients. Covered entities participating in the $340 \mathrm{~B}$ program are also prohibited from using a group purchasing organization to purchase eligible outpatient drugs. ${ }^{8}$

Pharmaceutical manufacturers agree to charge a 340B ceiling price to covered entities by signing a Pharmaceutical Pricing Agreement (PPA) with the secretary of HHS. Manufacturers that participate in the Medicaid Drug Rebate Program must sign a PPA. 
The $340 \mathrm{~B}$ price is confidential but was estimated to be $51 \%$ of average wholesale price in 2005 (the most recent year available). ${ }^{9}$ A 2010 government study found that Medicare payments were $31 \%$ higher than acquisition costs for 340B hospitals, but only $1 \%$ higher than acquisition costs for non-340B hospitals. ${ }^{10}$ Thus, discounts can be substantial for covered entities.

\section{Program Eligibility}

To be eligible for program participation, providers must be 1 of 6 designated hospital types or be an entity that receives federal grants administered by different agencies within HHS. In 2014, there were nearly 27,000 covered entity sites in the 340B program (Table 1).

Hospitals must meet additional eligibility criteria that vary by hospital type. Five of the 6 hospital types must have a "disproportionate share hospital (DSH) adjustment percentage" above a specified level. ${ }^{11}$ The Patient Protection and Affordable Care Act (PL 111-148) expanded the hospital types eligible to participate in the 340B program. Hospitals_including DSHs, critical access hospitals, sole community hospitals, and children's hospitals-accounted for 12,343 sites, or $45.8 \%$ of the total. These sites are operated by about 2,100 hospital organizations. ${ }^{2}$

HRSA must approve eligible entities, and covered entities must recertify their eligibility every year. Each site within a multilocation health system must qualify independently. A 340B hospital's outpatient facility can participate in the 340B program only if it is an "integral" part of the hospital, which HRSA defines as "a reimbursable facility included on the hospital's Medicare cost report." ${ }^{\prime 2}$ Hospitals must register each clinic within an ambulatory care facility that seeks to access 340B pricing.

Covered entities are permitted to use drugs purchased at the $340 \mathrm{~B}$ price for all eligible individuals who meet HRSA's definition of a "patient." The original statute explicitly prohibits the resale or transfer of a discounted drug by a covered entity to a person "who is not a patient of the covered entity." HRSA has also stated that a patient must receive health care services other than drugs from the $340 \mathrm{~B}$-covered entity. ${ }^{13}$ The statute, however, does not define the term "patient," so covered entities interpret the HRSA definition differently.

\section{Role of Contract Pharmacies}

A covered entity can purchase and dispense 340B drugs through internal or external (contract) pharmacies. In 1996, HRSA permitted some eligible entities to use a single contract pharmacy. In 2010, HRSA permitted eligible entities (including those that have an in-house pharmacy) to access 340B pricing through multiple, outside, contract pharmacies. ${ }^{14}$ Since the change in guidance, the number of contract pharmacies has jumped sharply. As of July 2014, there were 15,330 unique pharmacy locations, which accounted for $25 \%$ of total U.S. retail, mail, and specialty pharmacy locations. ${ }^{15}$ There were

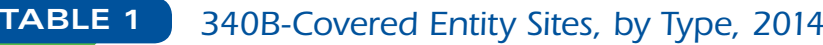

\begin{tabular}{|c|c|c|}
\hline Covered Entity Type & $\begin{array}{l}\text { Number of } \\
340 B \text { Sites }\end{array}$ & \begin{tabular}{|c} 
Percentage of \\
$340 \mathrm{~B}$ Sites
\end{tabular} \\
\hline Disproportionate share hospital & 9,292 & 34.5 \\
\hline Consolidated Health Center Program ${ }^{\mathrm{a}}$ & 6,097 & 22.7 \\
\hline Family planning (includes only Title X funded) & 3,540 & 13.2 \\
\hline Critical access hospital & 2,082 & 7.7 \\
\hline Sexually transmitted diseases & 1,930 & 7.2 \\
\hline Tuberculosis & 1,446 & 5.4 \\
\hline Ryan White Part C (formerly Title III) & 746 & 2.8 \\
\hline Sole community hospital & 644 & 2.4 \\
\hline Children's hospital & 325 & 1.2 \\
\hline Rural referral center & 322 & 1.2 \\
\hline $\begin{array}{l}\text { Tribal contract/compact with Indian Health } \\
\text { Service }\end{array}$ & 318 & 1.2 \\
\hline Comprehensive hemophilia treatment center & 105 & 0.4 \\
\hline Federally qualified health center look-alikes & 19 & 0.1 \\
\hline Urban Indian & 18 & 0.1 \\
\hline Black Lung Clinics Program & 11 & 0.0 \\
\hline Freestanding cancer hospitals & 7 & 0.0 \\
\hline Native Hawaiian Health Care Program & 5 & 0.0 \\
\hline Total & 26,907 & 100.0 \\
\hline \multicolumn{3}{|c|}{$\begin{array}{l}\text { Source: Author's analysis of Office of Pharmacy Affairs. } 340 \text { B database. Daily } \\
\text { reports. Covered entity daily report, as of July 23, } 2014.31 \\
\text { aIncludes community health centers, school-based programs, health care for the } \\
\text { homeless programs, migrant health programs, and public housing primary care } \\
\text { programs entities. }\end{array}$} \\
\hline
\end{tabular}

4,801 covered entity sites ( $18 \%$ of total 340B sites) with at least one contract pharmacy relationship.

Most 340B contract pharmacies are retail pharmacies, thereby extending 340B pricing to a broader set of patients than the hospital pharmacy itself might have served. Walgreens is the biggest participant, with $37 \%$ of all 340B contract pharmacy locations. As of July 2014, Walgreens had 5,735 locations acting as 340B contract pharmacies. The other major chainsCVS, Rite Aid, Walmart, Kroger, and Safeway-accounted for a combined 4,085 locations. There are also thousands of independent drugstores and small chains that participate. Mail pharmacies also play a role. The Walgreens' Tempe, Arizona, mail pharmacy is a contract pharmacy for more than 500 different providers. ${ }^{15}$

The contract pharmacy process is complex and can be confusing. While it is not possible to describe all possible arrangements, for illustrative purposes, Figure 1 depicts a typical flow of funds and products for a 340B contract pharmacy arrangement between a hospital and a contract pharmacy. The activities and roles in a typical 340B contract pharmacy arrangement are as follows:

1. A patient with commercial insurance fills a prescription at a retail or mail pharmacy.

2. The pharmacy is reimbursed by the patient's third-party insurance, per the terms of any network agreement. A portion 


\section{FIGURE 1 Illustrative Flow of Funds and Products for a 340B Contract Pharmacy Network ${ }^{a}$}

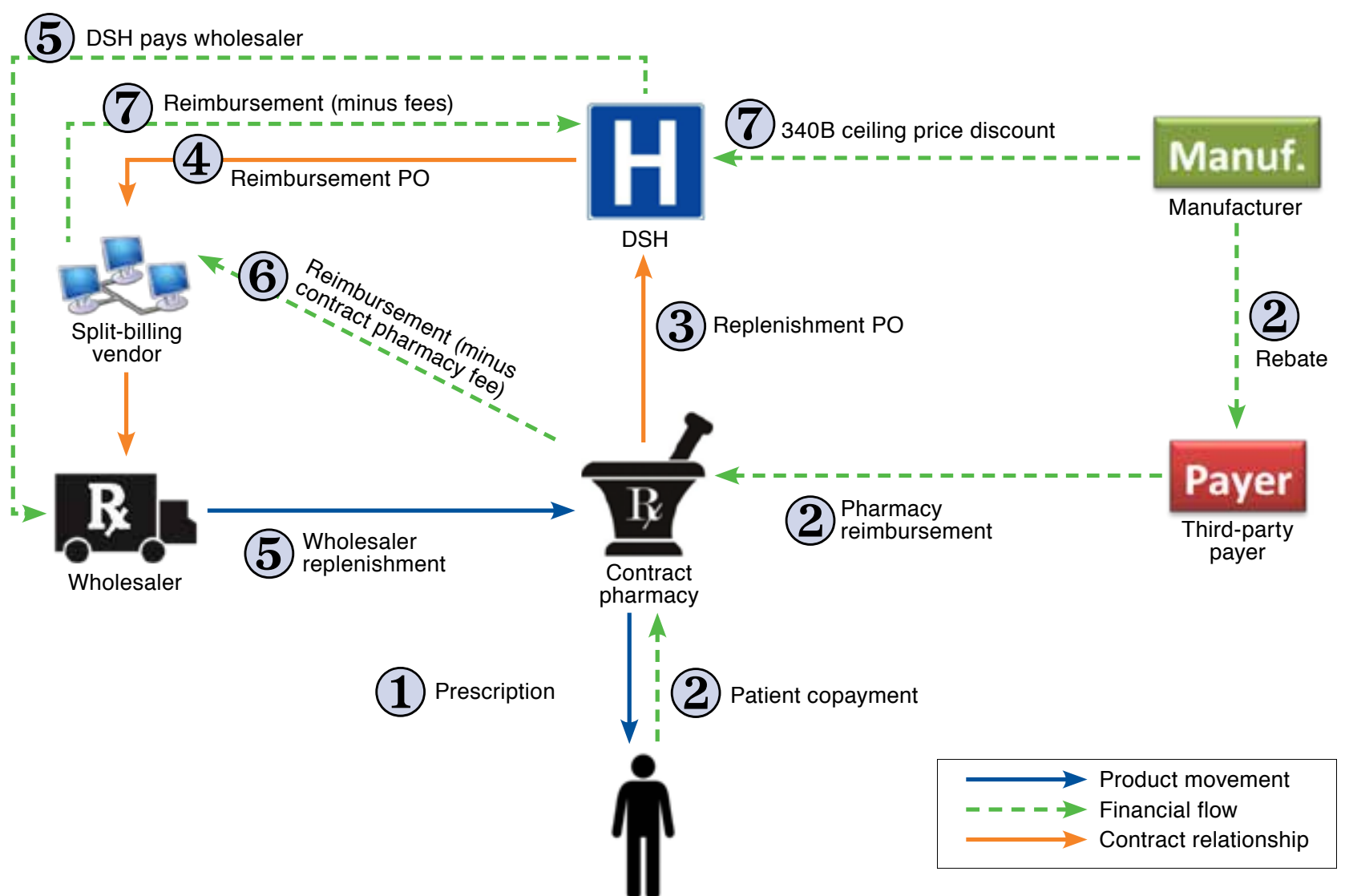

Source: Author's research.

aThis exhibit illustrates the most common arrangements between a 340B hospital and its contract pharmacy. It is not intended to be a complete representation of every type of financial, product flow, or contractual relationship in the marketplace.

$D S H=$ disproportionate share hospital; $P O=$ purchase order.

of the prescription cost is paid by the patient, according to the patient's pharmacy benefit plan. The manufacturer pays any formulary rebates to the third-party payer.

3. Using patient data provided by the $340 \mathrm{~B}$ entity, a splitbilling contract pharmacy software vendor screens for prescriptions from eligible patients. For prescriptions that meet profit and other criteria, the pharmacy submits a replenishment order to the $340 \mathrm{~B}$ entity, such as a DSH. Different entities can have different standards for identifying 340B-eligible prescriptions.

4. The hospital submits a replenishment order to its primary wholesaler.

5. The wholesaler replenishes the pharmacy's inventory but invoices the hospital, which pays the wholesaler at the 340B contract price. This process is called a ship-to/bill-to arrangement.
6. The pharmacy transfers its total reimbursement (from steps 1 and 2) to the software vendor, less the fee paid to the contract pharmacy. In some situations, the reimbursement from step 2 may be allocated by the payer to the pharmacy, hospital, and software vendor.

7. The hospital receives the total reimbursement, minus the contract pharmacy fee and the software vendor fee. The wholesaler submits a chargeback transaction to the manufacturer for the difference between the 340B price paid by the 340B-covered entity and the wholesaler's acquisition cost.

In this example, the hospital can profit from the difference between a contract pharmacy's reimbursement (minus fees to the contract pharmacy and software vendor) and the entity's 340B acquisition cost. 


\section{Challenges for Managed Care Pharmacy}

The rapid growth of 340B contract pharmacies raises troubling issues for third-party payers, pharmacy benefit managers, and other managed care participants. We focus on 4 crucial areas: formulary rebates, profits from managed care paid prescriptions, disruption of managed care pharmacy networks, and reduced generic dispensing rates.

\section{Formulary Rebates}

As 340B contract pharmacies penetrate retail networks, managed care organizations may receive lower formulary rebates from manufacturers and incur higher net pharmacy benefit reimbursement expenses. The $340 \mathrm{~B}$ statute prohibits manufacturers from having to provide a discounted $340 \mathrm{~B}$ price and a Medicaid drug rebate for the same drug. Covered entities are required to follow HRSA rules to prevent such "duplicate discounts."16 The prohibition on duplicate discounts applies to traditional Medicaid arrangements as well as Medicaid programs operated by managed care organizations, also known as Managed Medicaid.

However, it can be difficult to identify prescriptions for Managed Medicaid beneficiaries in contract pharmacy arrangements. Administrators of $340 \mathrm{~B}$ contract pharmacy programs cite insufficient information from state Medicaid agencies and plan identifiers that are not exclusive to Medicaid. ${ }^{17}$ Consequently, pharmaceutical manufacturers may be inappropriately paying duplicate discounts on these prescriptions. There are no public data to document the extent of this problem. One privately funded study estimated that in 2014 Managed Medicaid enrollees filled more than 3.4 million prescriptions at $340 \mathrm{~B}$ contract pharmacies. ${ }^{18}$ This figure is likely to grow with Medicaid expansion under the Patient Protection and Affordable Care Act, coupled with states shifting Medicaid beneficiaries to managed care and covered entities' increasing contract pharmacy arrangements. HRSA recently stated, however, that the database used to protect pharmaceutical manufacturers from paying duplicate discounts does not necessarily include Managed Medicaid claims. ${ }^{19}$

Unlike the provisions in Medicaid, there are no statutory protections for prescriptions paid by commercial third-party payers or Medicare Part D plans. Unless manufacturers and managed care organizations (MCOs) negotiate contract language prohibiting duplicate discounts, manufacturers will also pay rebates on the same prescriptions to commercial payers for products that covered entities purchase at 340B prices. Neither MCOs nor manufacturers can readily identify which prescriptions have been dispensed to $340 \mathrm{~B}$ patients. Since 340B-eligible prescriptions may not be identified until after the claim has been processed, pharmacies generally do not know whether a prescription relates to $340 \mathrm{~B}$.

The National Council for Prescription Drug Programs, which sets electronic communication standards for pharmacy care, allows the identification of an individual prescription's status under the 340B Drug Pricing Program. ${ }^{20}$ However, most hospitals and contract pharmacies do not regularly use this voluntary standard. Some 340B advocates have argued that it is impossible for pharmacies to comply with such standards, because a pharmacy would have to reverse and resubmit each 340B claim. ${ }^{21}$ Manufacturers would be justified in reducing managed care formulary rebates based on presumed 340B dispensed claims.

Even if we assume that these prescriptions could be more easily identified, third-party payers face an increased risk that formulary rebates paid by manufacturers will be reduced due to dispensing claims captured as 340B instead of third-party payer. Normally, formulary rebates reduce a third-party payer's net prescription costs.

\section{Profits from Managed Care Paid Prescriptions}

Since $340 B$ prescriptions at contract pharmacies cannot be identified at the time of adjudication, third-party payers reimburse $340 \mathrm{~B}$ and non-340B outpatient prescriptions at the same rate. Therefore, a 340B entity profits from prescriptions that are paid at nondiscounted rates by commercial payers and Medicare. Payers and beneficiaries could theoretically pay lower rates, although that would reduce profits for the 340B entities. In nearly all circumstances, Medicare and commercial payers cannot identify the extent of these profits, because covered entities are not required to report the payer for $340 \mathrm{~B}$ prescriptions.

Covered entities are earning substantial profits on these prescriptions. Senator Charles Grassley (R-IA) investigated 3 North Carolina hospitals. In a letter to HRSA, Grassley described "how hospitals are reaping sizeable 340B discounts on drugs and then turning around and upselling them to fully insured patients covered by Medicare, Medicaid, or private health insurance in order to maximize their spread." ${ }^{22}$ Documents released from that investigation showed that the majority of $340 \mathrm{~B}$ claims came from prescriptions paid by Medicare, Medicaid, and commercial third parties. Only 1 in 20 patients served in 2012 by Duke University Health System's 340B pharmacy was uninsured. The remaining 95\% had prescription costs paid by Medicare, Medicaid, or private insurance. According to an article in the April 3, 2013, edition of the Charlotte News Observer, "Duke University Hospital purchased $\$ 65.8$ million in drugs through the discount program, which saved $\$ 48.3$ million. It sold the drugs to patients for $\$ 135.5$ million, for a profit of $\$ 69.7$ million. The profit would have been $\$ 21.4$ million if Duke had not participated." ${ }^{23}$

A further challenge arises because covered entities and their software vendors classify outpatient prescriptions as "340B eligible" via nonpublic processes that are not subject to any formal regulations. Because of the lack of regulations, different entities have different standards for identifying 340B-eligible prescriptions. The Office of Inspector General (OIG) described 4 
common scenarios that would result in differing determinations of $340 \mathrm{~B}$ eligibility across covered entities. ${ }^{17}$ The OIG noted that "two covered entities may categorize similar types of prescriptions differently (i.e., 340B-eligible versus not 340B-eligible) in their contract pharmacy arrangements." In a separate report, the Government Accountability Office noted, "some covered entities may be broadly interpreting the definition to include individuals such as those seen by providers who are only loosely affiliated with a covered entity and thus, for whom the entity is serving an administrative function and does not actually have the responsibility for care."24

Covered entities' use of 340B profits is an especially controversial issue. As the OIG noted in a February 2014 report: "[T]he 340B statute speaks only to covered entities' eligibility and compliance; it does not specify how savings from the 340B program should be used." ${ }^{\prime 7}$ Notably, covered entities are not specifically obligated to share any $340 \mathrm{~B}$ savings with financially needy or uninsured patents, nor are they required to disclose how they use profits from the $340 \mathrm{~B}$ program. Indeed, there is evidence that uninsured and indigent patients do not always benefit from 340B drug discounts earned from commercially paid prescriptions dispensed by contract pharmacies.

The small amount of public information about the operation of 340B contract pharmacy arrangements paints a dismal picture for uninsured patients. In the OIG's only study of contract pharmacies, 5 out of the 15 hospitals offered uninsured patients the $340 \mathrm{~B}$ discount prescription price. ${ }^{17}$ The other 10 hospitals' contract pharmacies required uninsured patients to pay the full, non-340B price, even though hospitals were purchasing the drugs at the deeply discounted 340B price.

\section{Disruption of Managed Care Pharmacy Networks}

The rapid growth of $340 \mathrm{~B}$ contract pharmacies may be compromising relationships MCOs have with their pharmacy networks. MCOs establish a network of pharmacies so their beneficiaries can readily obtain their prescriptions. Network pharmacies accept discounted pricing in exchange for access to a plan's members.

Most 340B entities have small networks, but some operate unusually large ones. About 1,000 providers (4.1\% of total covered entities) have contract pharmacy networks with 6 to 25 pharmacies, accounting for one third of contract pharmacy arrangements. ${ }^{25} \mathrm{An}$ additional 300 health care providers (1.2\% of total covered entities) account for nearly half of all contract pharmacy relationships. This latter group operates contract pharmacy networks averaging 59 pharmacies but have networks as large as 276 pharmacies. Often, nearly all of a drugstore chain's locations in a city become part of a provider's 340B contract pharmacy network. Large networks threaten to disrupt traditional managed care contracting strategies. Rather than earning traditional dispensing spreads and fees, 340B contract pharmacies earn per-prescription fees paid by the $340 \mathrm{~B}$ entity. These fees can include fixed dollar payments as well as revenue-sharing arrangements. Thus, a pharmacy trades its normal profit margin for the contract pharmacy fees. Given substantial profit opportunities, a 340B entity can afford fees that often exceed a pharmacy's typical profits from dispensing a third-party-paid prescription.

It is not known whether 340B entities are monitoring these large networks, or whether they monitor out-of-state mail pharmacies. Covered entities are also not required to justify such large networks on the basis of access needs for vulnerable populations. Given HRSA's vague definition of an "eligible patient," hospitals have an incentive to create broad networks that generate revenue from as many fully insured prescriptions as possible. HRSA conducts program integrity audits; however, these audits do not report on whether covered entities monitor their sites. Pharmacy profitability from these contract arrangements is unknown, so managed care executives cannot analyze, understand, or predict the potential impact on network behavior. In 2013, Senator Grassley asked a large national chain to provide details about its 340B contract pharmacy operations. He requested information on "profits generated as a result of participating in the 340B program as a contract pharmacy." 26 Grassley also asked for details on the financial arrangements between Walgreens, a 340B-covered entity, and a split-billing software vendor. A response has yet to be made public.

\section{Reduced Generic Dispensing Rates}

Covered entities' profits from 340B prescriptions may be reducing generic dispensing rates, which would raise costs for third-party payers. For hospitals, the greatest 340B purchase discounts come from brand-name drugs. This discount can encourage the $340 \mathrm{~B}$ entity to prescribe brand-name drugs when equivalent generic alternatives exist. Prescribing physicians may even be encouraged to issue "dispense as written" directions as a way of supporting their institution. Consistent with this supposition, one recent study of contract pharmacy dispensing activity found that the generic dispensing rate was statistically significantly lower for 340B prescriptions when compared with all prescriptions. ${ }^{27}$

The substitution of less-expensive generic drugs for brandname drugs is a significant factor behind slowing growth in pharmacy spending. Third-party payers face the risk of increased costs when a contract pharmacy negotiates a fee arrangement based on 340B revenues or profits. Given substantial profit opportunities, a 340B entity can often afford fees that exceed a pharmacy's typical gross profit from dispensing a third-party-paid prescription. There are no public data available to analyze generic dispensing rates for 340B-eligible prescriptions to assess this risk.

\section{Outlook}

HRSA has issued proposed rules in areas in which it has specific congressional authorization, including civil monetary penalties for manufacturers, calculation of the 340B ceiling 
price, and administrative dispute resolution. In August 2015, HRSA also proposed the 340B Drug Pricing Program Omnibus Guidance $^{28}$ to address some of the policy issues raised by various stakeholders and industry participants. This guidance included the following items of particular interest to managed care pharmacy:

- Eligible patient definition

- Covered entities' oversight of contract pharmacies

- Pharmacy replenishment models

- Duplicate discounts in Managed Medicaid prescriptions

This proposed guidance, however, did not address the following issues: disclosure of covered entities' financial arrangements with contract pharmacies, requirements for covered entities to identify $340 \mathrm{~B}$ prescriptions, and size of contract pharmacy networks. HRSA received 1,264 comments on its proposed guidance, which it plans to finalize by late summer $2016 .^{29}$

Congress is showing renewed interest in the 340B program operations. An "explanatory statement" accompanying the U.S. fiscal 2015 spending bill stated, "There are concerns that HRSA has been unable to demonstrate that the $340 \mathrm{~B}$ program benefits the most vulnerable patients. In order to best serve the public need, the program should examine its ability to ensure patients' access to 340B savings for outpatient drugs. HRSA is directed to work with covered entities to better understand the way these entities support direct patient benefits from 340B discounted sales." 30

The 340B program has a large and growing influence over managed care pharmacy. To date, lobbying efforts around the 340B program have been intense. Most of these activities have come from hospitals, which benefit from the current unregulated environment, and the pharmaceutical manufacturers providing the discounted prices. Managed care should become more engaged in discussions on how the $340 \mathrm{~B}$ program evolves and offer policy proposals to mitigate the challenges it is encountering as a result of $340 \mathrm{~B}$ program policies.

In addition, much of what we know about the 340B drug discount program comes from government agency reports and non-peer-reviewed studies often funded by organizations with 340B program interests. There is an urgent need for objective, peer-reviewed research on the 340B program's costs, benefits, and implications for managed care pharmacy and practice.

\section{Author}

ADAM J. FEIN, PhD, is President, Pembroke Consulting, Philadelphia, Pennsylvania.

AUTHOR CORRESPONDENCE: Adam J. Fein, PhD, Pembroke Consulting, 1515 Market St., Ste. 960, Philadelphia, PA 19102

Tel.: 215.523.5700; E-mail: afein@pembrokeconsulting.com.

\section{DISCLOSURES}

No outside funding supported this paper. Fein reports receiving personal fees from multiple biopharmaceutical, other pharmaceutical manufacturers, and associations related to the pharmaceutical industry.

\section{REFERENCES}

1. Pollack A. Dispute develops over discount drug program. New York Times. February 12, 2013. Available at: http://www.nytimes. com/2013/02/13/business/dispute-develops-over-340b-discount-drugprogram.html. Accessed December 2, 2015. These dollar figures represent purchases at the discounted $340 \mathrm{~B}$ price.

2. Winter A, Zabinski D. The 340B Drug Pricing Program. MedPAC. November 6, 2014. Available at: http://www.medpac.gov/documents/ november-2014-meeting-presentation-the-340b-drug-pricing-program. pdf?sfvrsn=0. Accessed December 2, 2015.

3. Fein AJ. 340 B is taking over the hospital market-with a $25 \%$ share. Drug Channels (blog). February 25, 2014. Available at: http://www. drugchannels.net/2014/02/exclusive-340b-is-taking-over-hospital.html Accessed December 2, 2015.

4. Fein AJ. One in four U.S. pharmacies is now a $340 \mathrm{~B}$ contract pharmacy. Drug Channels (blog). July 15, 2014. Available at: http://www. drugchannels.net/2014/07/one-in-four-us-pharmacy-locations-is.html. Accessed

December 2, 2015.

5. U.S. House of Representatives. H.Rept 102-384, part 2: Medicaid and Department of Veterans Affairs Drug Rebate Amendments of 1992 Summary available at: https://www.congress.gov/bill/102nd-congress/ house-bill/2890. Accessed December 2, 2015.

6. What's in store for 340B in 2015 (part 1). Drug Discount Monitor. January 8, 2015. Available at: http://www.cpca.org/cpca2013/assets/ File/Health-Center-Information/340B/2015-29-1\%20Whats\%20In\%20 Store\%20for\%202015\%20Part\%201-4.pdf. Accessed December 2, 2015.

7. Health Resources and Services Administration. Eligibility \& registration. Available at: http://www.hrsa.gov/opa/eligibilityandregistration/ index.html. Accessed December 2, 2015.

8. Health Resources and Services Administration. Notice regarding 340B Drug Pricing Program—statutory prohibition on group purchasing organization participation. February 7, 2013. Available at: http://www.hrsa. gov/opa/programrequirements/policyreleases/prohibitionongpoparticipation020713.pdf. Accessed December 2, 2015.

9. Congressional Budget Office. Prices for brand-name drugs under selected federal programs. June 2005. Available at: http://www.cbo.gov/ sites/default/files/cbofiles/ftpdocs/64xx/doc6481/06-16-prescriptdrug.pdf. Accessed December 2, 2015.

10. U.S. Department of Health and Human Services, Office of Inspector General. Memorandum report: payment for drugs under the hospital outpatient prospective payment system, OEI-03-09-00420. October 22, 2010. Available at: http://oig.hhs.gov/oei/reports/oei-03-09-00420.pdf. Accessed December 1, 2015.

11. Avalere Health. The 340B Drug Discount Program: a review and analysis of the 340B program. Winter 2013. Available at: http://340breform. org/userfiles/340b\%20white\%20paper\%20final.pdf. Accessed December 2, 2015. The DSH computation can be found at: http://www.cms.gov/ Medicare/Medicare-Fee-for-Service-Payment/AcuteInpatientPPS/dsh.html. Accessed December 1, 2015.

12. Health Resources and Services Administration. Notice regarding section 602 of the Veterans Health Care Act of 1992-inclusion of outpatient hospital facilities. 59 Federal Register 29300 (June 6, 1994). Available at: http://www.hrsa.gov/opa/programrequirements/federalregisternotices/outpatienthospitalfacilities060694.pdf. Accessed December 2, 2015. 
13. HRSA states: "An individual will not be considered a patient of the covered entity if the only health care service received by the individual from the covered entity is the dispensing of a drug or drugs for subsequent self-administration or administration in the home setting." For the complete definition, see Health Resources and Services Administration, Eligibility \& registration. Available at: http://www.hrsa.gov/opa/eligibilityandregistration/ index.html. Accessed December 2, 2015.

14. Health Resources and Services Administration. Notice regarding 340B Drug Pricing Program-contract pharmacy services. 75 Federal Register 10272 (March 5, 2010). Available at: http://www.gpo.gov/fdsys/pkg/ FR-2010-03-05/pdf/2010-4755.pdf. Accessed December 2, 2015.

15. Office of Pharmacy Affairs. 340B database. Daily reports. Daily contract pharmacy report, as of July 1, 2014. (Published daily). Available at: https:// opanet.hrsa.gov/340B/Views/Reports/Default. Accessed December 1, 2015.

16. Health Resources and Services Administration. Medicaid exclusion file/ duplicate discount prohibition. Available at: http://www.hrsa.gov/opa/programrequirements/medicaidexclusion/index.html. Accessed December 2, 2015.

17. U.S. Department of Health and Human Services, Office of Inspector General. Memorandum report: contract pharmacy arrangements in the $340 \mathrm{~B}$ program, OEI-05-13-00431IG. February 4, 2014. Available at: http://oig.hhs. gov/oei/reports/oei-05-13-00431.pdf. Accessed December 2, 2015.

18. Vandervelde A. Estimate of managed Medicaid prescription volume in 340B contract pharmacies. BRG Health Analytics. Available at: http://www. thinkbrg.com/assets/htmldocuments/Estimate\%20of\%20Managed $\% 20$ Medicaid\%20Prescription\%20Volume\%20in\%20340B\%20Contract\%20 Pharmacies.pdf. Accessed December 3, 2015.

19. Health Resources and Services Administration. Clarification on use of the Medicaid exclusion file. December 12, 2014. Available at: http://www. hrsa.gov/opa/programrequirements/policyreleases/clarificationmedicadexlusion.pdf. Accessed December 2, 2015.

20. National Council for Prescription Drug Programs. 340B information exchange reference guide version 1.0. July 2011. Available at: http://www. ncpdp.org/NCPDP/media/pdf/340B_Information_Exchange_ReferenceGuide_vl-0.pdf. Accessed December 2, 2015.

21. Safety Net Hospitals for Pharmaceutical Access (SNHPA). Letter to Jason A. Helgerson, Medicaid director and deputy commissioner, New York State Department of Health, on concerns regarding identification of 340B Medicaid managed care claims. December 19, 2011. Available at: http://www.snhpa. org/files/SNHPA_Letter_and_Testimony_Regarding_NY_340B_Medicaid_ Managed_Care_Claims_12-19-2011.pdf. Accessed December 2, 2015.
22. Grassley CE. Letter to Mark K. Wakefield, administrator, Health Resources and Services Administration. March 27, 2013. Available at: http:// www.grassley.senate.gov/sites/default/files/about/upload/2013-03-27-CEGto-HRSA-340B-Oversight-3.pdf. Accessed December 2, 2015.

23. Alexander A, Neff J, Garloch K. Senator: hospitals profited on drugs for poor, uninsured. Charlotte News Observer. April 3, 2013. Available at: http:// www.charlotteobserver.com/2013/04/03/3956004/senator-3-nc-nonprofithospitals.html. Accessed December 2, 2015.

24. U.S. Government Accountability Office. Report to congressional committees: manufacturer discounts in the 340B program offer benefits, but federal oversight needs improvement. September 2011. Available at: http://www.gao. gov/assets/330/323702.pdf. Accessed December 2, 2015.

25. Fein AJ. One percenters: the real facts behind hospitals' 340B contract pharmacy mega-networks. Drug Channels (blog). July 16, 2014. Available at: http://www.drugchannels.net/2014/07/one-percenters-real-facts-behind. html. Accessed December 2, 2015.

26. Grassley CE. Letter to Gregory Wasson, president and CEO, Walgreens. July 31, 2013. Available at: http://big.assets.huffingtonpost.com/ Grassley340B.pdf. Accessed December 2, 2015.

27. Clark BL, Hou J, Chou CH, Huang ES, Conti R. The 340B discount program: outpatient prescription dispensing patterns through contract pharmacies in 2012. Health Aff (Millwood). 2014;33(11):2012-17.

28. Health Resources and Services Administration. 340B Drug Pricing Program omnibus guidance. 80 Federal Register 52300 (August 28, 2015) Available at: https://www.federalregister.gov/articles/2015/08/28/201521246/340b-drug-pricing-program-omnibus-guidance. Accessed December 11, 2015.

29. HRSA aims to issue final 340B mega-guidance by late summer. Drug Discount Monitor. December 1, 2015.

30. Division G-Departments of Labor, Health and Human Services, and Education, and Related Agencies Appropriations Act, 2015. Available at: http://docs.house.gov/billsthisweek/20141208/113-HR83sa-ES-G.pdf. Accessed December 2, 2015.

31. Office of Pharmacy Affairs. 340B database. Daily reports. Covered entity daily report, as of July 23, 2014. (Published daily). Available at: https://opanet. hrsa.gov/340B/Views/Reports/Default. Accessed December 1, 2015. 